\title{
Assertiveness and Academic Achievement Motivation of Adolescent Students in Selected Secondary Schools of Harari Peoples Regional State, Ethiopia
}

\author{
Galata Sitota*
}

Department of psychology, College of Education and Behavioral Sciences, Haramaya University

Corresponding author: Galata Sitota, E-mail:galatasitota@yahoo.com

\begin{tabular}{l} 
ARTICLE INFO \\
\hline Article history \\
Received: July 17, 2018 \\
Accepted: October 29, 2018 \\
Published: October 31, 2018 \\
Volume: $6 \quad$ Issue: 4 \\
\hline
\end{tabular}

Conflicts of interest: None Funding: None

\begin{abstract}
The present study aimed to examine the relationship between assertiveness and academic achievement motivation of adolescent students in selected secondary schools of Harari Peoples Regional State among a sample of 332 (145 males and 187 females). Data were collected through the twenty-four-item of academic achievement motivation (AAM) inventory with four-point rating scale that was adapted from previous versions and scales for assessing Assertive Behaviour a thirty-item instrument with six-point rating scale ranging from $(+3$, very characteristic of me to -3 , very uncharacteristic of me) that was adapted from previous research. Data were analyzed employing a blend of both descriptive and inferential statistical methods that successively conducted to examine the level of assertive behavior employing one-sample mean test and combined effects of independent variables on dependent variable (academic achievement motivation) were made employing regression analysis. Findings indicated that; Harari peoples regional state adolescent student's participated in present study were scored low on the assertiveness; male adolescents were found to be better in their levels of assertiveness than their female adolescent counterparts. With pertaining to the relationship between assertiveness and academic achievement motivation was concerned, there was a statistically significant positive relationship between them. Additionally, it was found that there was a statistically significant positive relationship between parental educational status and assertiveness. Unlike assertiveness and parental educational status, sex appeared to be a less important factor in explaining adolescents' academic achievement motivation. Attempts were made to explain findings within the existing ecological and socio-cultural practices of the study area. Recommendations were also suggested as to how to properly address the gaps noted in this research.
\end{abstract}

Key words: Adolescent Assertiveness, Academic Achievement Motivation, Parental Education Status, Harar

\section{INTRODUCTION}

To lead successful life being assertive is crucial. Whether the purposes of individuals are to be successful in education, work, social life and the like, being assertive is very important. Especially, since the period of adolescence is the time when individuals are attending their education at high school levels and beyond and also preparing themselves for adult roles and responsibilities, they are supposed to be assertive enough. Assertiveness can help students improve communication skill. This skill helps students have more time to study and to achieve good performance in their academic achievement (Huurre, Aro, Rahkonen, \& Komulainen, 2006). Adolescence is one of the most significant and intricate life stages. Issues and difficulties caused by the puberty make adolescence a period of crisis. Assertiveness is a skill which can empower the teenagers' self-efficacy and positively impress their interactions with others to cause their trust and self-esteem. The defects in this skill can result in many problems for young people. Assertiveness is of great importance in adolescents due to their age and peer group pressure. Furthermore, it can protect them against the factors threatening their health. Assertiveness is closely associated with self-confidence, self-esteem, anxiety (Ghodrati, Tavakoli, Heydari, \& Akbarzadeh, 2016).

Though different scholars explain the concepts of assertiveness in different ways, conceptually the notion of their definition is well-nigh similar. For example, Seguided (1995, as cited in Ghodrati et al. 2016) define assertiveness as a healthy way of communication and the ability to speak up for ourselves in way that is honest and respectful manner. Assertive people care about other people's feelings and therefore phrase their requests or compliant in a polite but firm manner. Assertiveness is a learned fundamental interpersonal communication skill that helps individuals meet the social demand of society. According to Carrobles (1986, as cited in Ghodrati et al. 2016), such behavior is not an individual's stable and general traits; a person may be sufficiently assertive in some situation and behave according to certain prototype in one's social interactions, 
such as assertive or socially skilled behavior, passive behavior, and at the other extreme, aggressive behavior. Assertiveness behavior involves many things, the expression of one's genuine feeling, standing up for one's legitimate rights and refusing unreasonable request, (Rathus, 1998). It means with standing undue social influences, disobeying arbitrary group standards.

In general, assertiveness is the quality of being self-assured and respecting others as well. They are neither passive nor allow others to abuse them. Moreover, assertive people pursue tactfully respecting others' wants and needs. Those with poor assertiveness may be passive (low assertiveness) or aggressive (aggressive behaviors).

According to Lange and Jakubowski (1976, as cited in Eskin, 2003), people high in assertiveness are more self-actualized than people low in assertiveness because assertive behavior leads to one's needs being respected and fulfilled. Galassi et al. (1994) suggested that assertive people are communicative, free-spirited, secure, self-assured, and able to influence and guide others. Della and Namara (2001, as cited in Huurre et al. 2006) did a study at Ohio University to evaluate the impact of assertive behaviors on inter- and intrapersonal interactions in crisis. The results showed that poor assertiveness was accompanied by more anxiety level. They tend to neglect their own rights. On the other hand, higher assertiveness was along with a higher sense of cooperation and interaction which results in more peace and convenience.

Need achievement motivation as defined by McLelland (1885) has to do with peoples' desire to achieve great feat in life. Such people seem to have an inner motivator that propels them towards achievement (despite odds and limitations). People with a high need for achievement (nAch) seek to excel and thus tend to avoid both low-risk and highrisk situations. Achievers avoid low-risk situations because the easily attained success is not a genuine achievement. In high-risk projects, achievers see the outcome as one of chance rather than one's own effort. High nAch individuals prefer work that has a moderate probability of success, ideally a $50 \%$ chance. Achievers need regular feedback in order to monitor the progress of their achievements. They prefer either to work alone or with other high achievers.

As regard to how assertiveness affects students' academic performance, researchers have established that assertiveness can help a student improve communication skills, self-esteem, and decision-making ability. It can help overcome shyness and anger. Being assertive can lead students having more time to study. All of these can positively impact a student's conceptions about school performance.

On the contrary, when a student behaves or interacts in a non-assertive manner, such a student allows his own needs to go unmet. There are many ways in which this could be detrimental to a student's academic life. One of the most common ways this occurs is when one allows other people to take up time that had set aside for study. For instance, if you have an assignment due the following day and your friends ask you to go out with them the night before, a person who was non-assertive might feel unable to say 'no', and would end up going out instead of doing the assignment. Another way non-assertiveness can affect one's academic life would be when one believes, correctly, that he deserved more marks for an assignment but take the non-assertive approach of doing nothing about it. This could make the difference between passing or failing the course overall. All of these can affect a student's academic motivation and performance (Oladipo, Arigbabu \& Rufai, 2012).

As regard to the relationship between assertiveness and academic achievement, study conducted in Iran on high school students by Ghodrati et al. (2016) indicated that there was a significant correlation between assertiveness and academic achievement. In support of this idea study conducted in Nigeria on high school students by Oladipo et al. (2012) indicated that need-achievement correlated significantly with assertiveness. Contrary to these findings, Elma (2017) argued that there is not significant relationship between assertiveness and academic performance in both sexes.

As regard to sex and assertiveness Oladipo et al. (2012) concluded that there is no significant relationship between need achievement and assertiveness among male students. A statistically significant relationship between need achievement and assertiveness is actually observed among female students. What it thus means is that, the more assertive a girl is, the higher her need for achievement and the more likely she better performed in her education. According to Eskin (2003), the level of assertiveness increased with an increase in the students' age, but this relationship was significant only in males but not in females.

Thus, in the face of such contradicting findings, it would not be possible to take a firm stand regarding the role of gender in academic achievement motivation and assertiveness, and the relationship between assertiveness and academic achievement motivation; hence, there is a need for further research in the area based on foregoing and the following justifications. First, despite the fact that being assertive is crucial importance in adolescents' academic motivation and performance, no study has been directed to set out the effects of assertiveness on students' academic motivation and performance in the study area. Second, not only adolescents, but also adults who could expect to lead their lives successfully need to be assertive enough; however, no study has been directed to examine the status of adolescent students' level of assertiveness in the study area. Third, in Ethiopian context, there is scientifically ungrounded hearsay that female are less assertive in compare to males; however, there was no scientific study has been directed to prove or disprove the unfounded information about assertiveness in the study area.

In an attempt to address the concerns raised issues, the following research questions were raised in this study: What was the level of students' assertiveness? Was there a statistically significant relationship between assertiveness and academic achievement motivation? Finally, was there a statistically significant difference between male and female adolescent students in their assertiveness?

\section{REVIEWS OF RELATED LITERATURE}

\section{Assertiveness}

Assertiveness is the ability to communicate opinions, needs, and feeling in a direct, honest and appropriate manner. People who are assertive know they have rights but also remember that 
other people have rights as well. Assertive people care about other people's feelings and therefore phrase their requests or compliant in a polite but firm manner. Assertiveness is defined as interpersonal behavior that allows the direct expression of one's feelings, without cognitive distortion or anxiety, combining verbal and non-verbal components, and the defense of ones right, while respecting those of other (Tunner, 1992).

\section{Previous Studies on Assertiveness}

As regard to the impacts of assertiveness on personality of individuals, Moon (2009) stated that assertive behavior resulted in different personalities such as aggressive behavior; aggression involves standing up for you in a way that is pushy push and inappropriate. Aggression offends the rights of other people. Therefore, people who have an aggressive style believe firmly in their own rights but may not believe that others have equal right. These usually have a strong need to complete or prove themselves. They sometimes feel deserve more respect and attention than other peoples do. Alternatively, although people with aggressive style may agree that other people have rights, but lose sight of this when they feel their own rights have been infringed upon. People who have an aggressive style tend to have poor communication skills. They usually get their own way by treading on others by being rude, pushy and insulting. This behavior may not be intentional but can be very hurtful. They are likely to have trouble developing or keeping close and affectionate relationship. Aggressive behavior includes physical and verbal attacks, threats, and insults. The other is passive behavior; a person with a passive style tends to put the need of others before their own. This maybe because they do not believe they have the right to assert themselves. They may believe that they are inferior and that their needs are not important enough to make a fuss about, alternatively, passive people could feel that it is too difficult to be assertive or that bit is much easier to late others make all the decisions. These people tend to believe that they are in competent or weak and thus have difficulty looking after them or making their own decision.

Although passive people may not always be happy with the decisions made by others, it usually seems easier to go along with the decisions and keep the peace rather than make a fuss. However, given time passive people may start to resent the fact that their needs are always over looked. The result may be low self-esteem, depression, anger, and many other emotional or physical complaints. Also, people who are very passive often lose the respect of others if they fail to stand up for their rights.

As regard to gender and assertiveness, Oladipo et al. (2012) concluded that there is no significant relationship between need achievement and assertiveness among male students. In support of this idea, Eskin (2003) stated that the level of assertiveness increased with an increase in the students' age, but this relationship was significant only in boys but not in females. Thus, it is difficult to take stand as regard to sex difference in assertiveness among adolescents.

With regard to the relationship between academic achievement and assertiveness, Moon (2009) stated that assertive students achieve more in their academic performance at secondary school. Since they have expressed their feelings, opinions, thoughts freely at the other extreme, students have displayed passive behavior in capable of expressing their thoughts and feelings to others. If they do so, they are self-defeating and behave with a lack of confidence. This causes them to be ignored by others, which, as a result, decreases their self-esteem. Compare to assertive person, an unassertive person shows a lack of self-respect, also displays some lack of confidence in others capacity to deal with frustration, responsibility, etc. Ultimately, they hope to appease others and avoid conflict which finally hamper their day to day lives in general and academic life in particular.

As pertaining to the importance of being assertiveness Jakubowski (1976, as cited in Moon, 2009) argued that assertive behavior is commonly associated with the ability to initiate and maintain reward interpersonal relationship in the business world and personal life. He also further stated that people high in assertiveness are more self-actualized than people low in assertiveness because assertive behavior leads to one's needs being respected and fulfilled, are communicative, free-spirited, secure, self-assured, and able to influence and guide others.

\section{METHODS}

As mentioned earlier, the purpose of this study was to set out the level of assertiveness and its relationship with adolescents' academic achievement motivation of adolescent students in selected secondary schools of Harari peoples regional state. In order to obtain the required information, descriptive survey research design was employed. This section describes, the study site, sampling techniques, instrument of data collection, and procedure followed in data collection.

\section{Study Site}

Harar is a city in Eastern Ethiopia, with a population of $\sim 122,000$ people. The city is approximately $526 \mathrm{~km}$ from the capital of Ethiopia, Addis Ababa, at an elevation of $1,885 \mathrm{~m} / 6,184 \mathrm{ft}$. The city of Harar (the second oldest - after Axum) derived its name from the much talked-about (and written-about) ethnic group - the Harari (known to other Ethiopians as Adere) - that once represented nearly $100 \%$ of the population inside its reputed wall but now form less than $15 \%$ far outnumbered by the Amara and Oromo. The city is located on a hilltop in the eastern extension of the Ethiopian Highlands.

Based on figures from the Central Statistical Agency in 2005 , Harar had an estimated total population of 122,000 , of whom 60,000 were males and 62,000 were females. According to the census of 1994, on which this estimate is based, the city had a population of 76,378. For centuries, Harar has been a major commercial Centre, linked by the trade routes with the rest of Ethiopia, the entire Horn of Africa, the Arabian Peninsula, and, through its ports, the outside world. Islam is the predominant religion with $69 \%$ of the population reporting themselves as adherents of the religion, followed by Orthodox Christianity (27\%). The ethnic compositions in the 
State include Oromo 52.3\%, Amhara 32.6\%, Harari 7.1\%, and Guragies 3.2\%. Harari language is the official language of the State followed by Afan Oromo as the second official language of the region. The dominant activity serving the inhabitants as a means of income in this town is cash crop products like chat. We can call Harar city as the symbol of smallest Ethiopia because it is the place were different ethnic groups are living together in harmony. Nowadays, Harar city is one the fastest growing cities in Ethiopia which attracts many adults including children that flow to the city from the rural area around the city and from other neighborhood cities. Pertaining to education, as Ethiopian Demographic and Health Survey, 2011 reported, over the fifth of Harari region's men is illiterate $(22.4 \%)$. And, only $30.3 \%$ of Harari women in the reproductive age of 15-49 have completed a secondary or higher education. It is also interesting to note that the highest percentage of men who smoked cigarettes $(26.6 \%)$ lived in Harari as did the highest percentage of women who chewed Chat $(39.2 \%)$. The highest proportion of men who chewed Chat (81.9\%) also lived in Harari.

\section{Participants}

The study involved students selected from Aboker and Abadir senior secondary and preparatory schools and Harari junior secondary school. In these schools, a total of 3421 (1943 female and 1478 male) students regularly attending their classes from grade nine to twelve during data collection. With regard to sample size determination, Neuman (1997) pointed out some guiding principles that are followed by conventional social science researchers for selecting representative samples for quantitative studies. As stated by Neuman, if the study population is 1000 or under, the sample ratio would need to be 300 (about 30\%) individuals, for a population of 10,000 the sample size would be 1000 (about 10\%); and for populations over 150,000 , smaller sampling ratios $(1 \%)$ are

Table 1. Personal background of respondents

\begin{tabular}{lccc}
\hline Variables & No & Percent \\
\hline Sex & & & \\
$\quad$ Male & 145 & 43.5 & \\
$\quad$ Female & 187 & 56.5 & \\
$\quad$ Total & 332 & 100 & \\
Parental educational status & & & \\
$\quad$ Illiterate & 21 & 6.32 & \\
1-4 & 111 & 33.43 & \\
5-8 & 61 & 18.37 & \\
9-12 & 42 & 12.65 & \\
Certificate & 32 & 9.63 & \\
Diploma & 36 & 10.84 & \\
$\quad$ Degree \& & 29 & 8.73 & \\
$\quad$ above & & & \\
Total & 332 & $100 \%$ & \\
Age & & & \\
\hline Minimum & Maximum & $M$ & \\
\hline 13 & 25 & & \\
\hline
\end{tabular}

acceptable. What this guideline makes clear is that as the target population increases, the sampling ratio decreases. In this case, the total sampling frame of the study is $3421(10 \%)$ of the sampling frame will be considered as participants' of the study. In order to give equal chance for both sexes, participants were stratified based on their sexes and then systematic random sampling method was employed. Accordingly, a sample of 332 (145 males and 187 females) were randomly selected and participated in the study whereas ten of the respondents were failed to fill and return the questionnaire back to the researcher.

\section{Instruments of Data Collection}

Self-report instruments were used to measure variables of interest. The instruments had three parts. Part one comprised structured items, mainly about the participants' demographic information, especially important for this study (sex, age and grade level), the second part of the instrument was 'Academic Achievement Motivation Self- Report Inventory" (AAM SRI) and the third part of the instrument was scale used for assessing assertive behaviour developed by Spencer in 1974 .

Academic Achievement Motivation Self- Report Inventory (AAM SRI) is a scale consisted of 24 items for participants to rate themselves on a four-point scale ranging from strongly agree to strongly disagree. The scale was adopted from previous research conducted on high school and college students' academic achievement motivation. In the Ethiopian context, the instrument was used by Daniel (1992) with a reliability coefficient of 0.67 , and Mulugeta (1998) and Kifle (2005) with an $\alpha$ value of 0.71. Moreover, Belay and Galata (2016) was found that the alpha value of this questionnaire was 0.76 . Originally, the scale consisted of 29 items. The adaptation began with backward and forward translation of the scale into the native languages of participants i.e., Afan Oromo and Amharic. Then, pilot test was conducted on a randomly selected sample of thirty students (15 males and 15 females) to check for item clarity as well as internal consistency of the items. Two items were found to have poor internal consistence with other items and therefore dropped from the scale improving the reliability coefficient from previous ones to $\alpha=0.79$

Scale used for Assessing Assertive Behavior (Rathus Assertiveness Schedule) is the scale consisted of 30 items for participants to rate themselves on six-point scale ranging from $(+3$, very characteristic of me and -3 , very uncharacteristic of me. Scoring $(+45)$ on the scale is considered as mean value. A mean score and above indicate that the individual is high on assertiveness, while a score below the mean indicates that the individual is low on assertiveness, as reported by Oladipo et al. (2012). This scale originally consists of 30 items with test-re test reliability of (0.78). The scale consists of items such as boldness, outspokenness, confidence, aggressive and the like. Before using this scale for actual data collection, the scale was tried out on randomly selected thirty students (15 males and 15 females). And then, internal item consistency analysis was made and accordingly test re-test reliability Cronbach alpha.76 was achieved and the scale used for final data collection as it is. 
Table 2. One sample t-test result on the status of student's level of assertiveness $\left(n_{i}=332\right)$

\begin{tabular}{|c|c|c|c|c|c|c|c|c|c|c|c|}
\hline Variable & No of items & Rating scale points & \multicolumn{4}{|c|}{ Observed values } & \multicolumn{3}{|c|}{ Expected values } & $t$ & $p$ \\
\hline Assertiveness & 30 & $(+3) \sim \sim(-3)$ & Min & $\max$ & mean & SD & $\min$ & $\max$ & mean & -9.12 & 0.001 \\
\hline & & & 11 & 78 & 37.5 & 4.31 & -90 & 90 & 45 & & \\
\hline
\end{tabular}

Table 3. Independent t-test result on the assertiveness between male and female respondents

\begin{tabular}{llcccccc}
\hline Variable & Groups & $\mathbf{N}$ & $\boldsymbol{M}$ & $\mathbf{d f}$ & $\mathbf{d f}$ & $\boldsymbol{t}$ & $\boldsymbol{p}$ \\
\hline Assertiveness & Male & 145 & 40.45 & 3.41 & 331 & 6.32 & 0.002 \\
& Female & 187 & 34.34 & 2.21 & & & \\
\hline
\end{tabular}

Table 4. Inter correlation among variables of interest $\left(\mathrm{n}_{\mathrm{i}}=332, P<0.05\right)$

\begin{tabular}{|c|c|c|c|c|}
\hline Predictor variables & 1 & 2 & 3 & 4 \\
\hline Assertiveness (1) & 1 & & & \\
\hline $\begin{array}{l}\text { Sex }(2)(=1 \text {, if male, }=0 \text {, if } \\
\text { female) }\end{array}$ & $0.45^{*}$ & 1 & & \\
\hline Parental educational status (3) & $0.67 *$ & 0.31 & 1 & \\
\hline $\begin{array}{l}\text { Academic achievement } \\
\text { motivation (4) }\end{array}$ & $0.71 *$ & $0.57 *$ & -0.42 & 1 \\
\hline
\end{tabular}

\section{FINDINGS}

This section shall present obtained findings based on data analysis. Collected data were analyzed employing both descriptive and inferential statistical methods. Following summarization of background of the participants, descriptive statistical methods were employed as to examine the level of students' assertiveness and to set out the relationship between assertiveness and academic achievement motivation person product moment correlation coefficient has been employed followed by independent t-test to scrutinize sex difference in their level of assertiveness if any. Table 1 presents summary of background of respondents.

As depicted in the Table 1, while $43.5 \%$ of participants were male, $56.5 \%$ of them were females. As regard to parental education status of respondents, about $60 \%$ of parents of respondents either illiterate or maximum of attended elementary school education. In connection with the ages of respondents, 17.4 mean values have reported.

The main interest of the present study was to pinpoint the status of respondents' levels of assertiveness. In view of that, one sample t-test was employed to examine the stated object and presented in the Table 2 as follows.

As shown in Table 2, the observed mean score (mean $=37.5)$ of students' level of assertiveness was far below the expected mean score $($ mean $=45)$. The expected mean score and above (45+) indicate that the individual is high on assertiveness, while a score below the expected mean indicates that the individual is low on assertiveness as reported by Oladipo et al. (2012). The observed difference was a statistically significant as one sample t-test result evidenced, $t(331)=-9.12, p<.05)$. This suggested that participants' level of assertiveness was found to be far below the expected level of assertiveness.
As far as adolescents' sex difference in their levels of assertiveness was concerned, independent t-test was employed to examine the sex difference among adolescents if there was any. Accordingly, the obtained result was presented as follows.

As it can be depicted in the Table 3, there was a statistically significant difference between male and female adolescents in their level of assertiveness, $\mathrm{t}(331)=6.32, \mathrm{p}<.002$, two tailed with a mean value of (40.45 males and 34.34 females) respectively.

To examine whether the relationship exist among variables of interest or not, Pearson product moment correlation coefficient was performed and the obtained results were presented as follows.

As it was indicated in the Table 4, there was a statistically significant relationship between assertiveness and sexes of respondents, $\rho(331)=0.45^{*}, p<.05$, two tailed. This means that male adolescents were better in their level of assertiveness than their female adolescent counterparts alike the result obtained through independent t- test that was reported in the Table 3. Moreover, it was found that there was a statistically significant relationship between assertiveness and parental educational status, $\rho(331)=0.67^{*}, p<0.05$, two tailed as it was reported in the same table. This result entails that as parental educational status increases, adolescents' level of assertiveness increases too. In addition to this, it was identified that there was a statistically significant strong positive relationship between assertiveness and students' academic achievement motivation, $\rho(331)=0.71, p<.05$, two tailed. This demonstrated that both variables increase together.

As far as cumulative effects of independent variables on dependent variables was concerned, the following table shows the effects of independent variables namely-assertiveness, parental educational status and sex on students' academic motivation by employing multiple regressions. Consequently, the results were presented as follows.

As it can be seen in the Table 5, the multiple regressions analysis result was demonstrated that about $24.2 \%$ $\left(R^{2}=0.241\right)$ of the variance in students' academic achievement motivation was explained by all the predictors together. Indeed only assertiveness, $t(331)=22.31 p<$. 05, two tailed and parental educational status, $t(331)=7.51, p<.05$, two tailed significantly predict students' academic motivation score respectively.

\section{DISCUSSION}

To be successful in all aspects of life especially in academic endeavor being assertive is very important. Unlike that of researcher's expectation that adolescent students' level of assertiveness around Harari peoples regional state could be higher because of community's cultural orientation that 
Table 5. Multiple regression analysis of predictors on dependent variables

\begin{tabular}{lccccc}
\hline Variables & Regression coefficient & Standard error 2.13 & Beta coefficient & $\boldsymbol{t}$ & $\boldsymbol{p}$ \\
\hline Assertiveness & 17.12 & 4.21 & 0.61 & 22.31 & 0.000 \\
Parental educational status & 8.12 & 2.12 & 0.34 & 7.51 & 0.003 \\
Sex & 0.31 & 1.21 & 0.01 & 0.71 & 0.67 \\
\hline
\end{tabular}

would possibly strengthen the quality of being assertive especially in the business arenas, the findings of this research tends to suggest that adolescent students participated in present study were scored low on the measurement of assertiveness. This may be attributed to different factors such as parental nurturing style in which in Ethiopian context being letting others use one's opportunities and giving priority to others was considered as acceptable behavior and fighting for one's benefit was considered as selfishness, which in turn developed a habit of withdraw in adolescents from being assertive.

With regard to sex difference among adolescents in their levels of assertiveness, male adolescents are found to be better in their levels of assertiveness than their female adolescent counterparts. The present finding is confirmed by the societal hearsay in which males are considered as better in their levels of assertiveness than their female adolescent counterparts. This may be attributed to parental nurturing style and societal expectations in which in our community females are detected to be submissive which thereby finally hamper females not to be assertive enough. Contrary to the present findings, Olapido et al. (2012) concluded that there was no significant relationship between need achievement and assertiveness among male students. The significant relationship between need achievement and assertiveness is actually observed among female students.

With pertaining to the relationship between assertiveness and academic achievement motivation significant and positive relationship were observed. Meaning, as the level of assertiveness increases adolescents academic achievement motivation also increases too. In support of this notion, Ghodrati et al. (2016) indicated that there was a significant correlation between assertiveness and academic achievement. In support of this idea study conducted in Nigeria on high school students by Olapido et al. (2012) indicated that need-achievement correlated significantly with assertiveness. Contrary to this finding Elma (2017) argued that there was no a statistically significant relationship between assertiveness and academic speech and communication in both sexes.

As it can be noted from the analysis, there was positive and significant relationship between parental educational status and assertiveness. This may be attributed to parenting in such a way that in compare to illiterate parents, educated parents would encourage their children to be open, speak out on their concerns, questions and let them express their idea as they want which in turn help them develop acceptable assertive behavior.

Unlike assertiveness and parental educational status sex appear less important factors in explaining adolescents' academic achievement motivation. The present finding is alike the report of Belay and Galata (2016) in which they conclude that sex found to play less important role in predicting adolescents' academic motivation.

\section{CONCLUSION}

The findings of this research generally suggest the following major conclusions regarding the relationship between assertiveness and academic achievement motivation of adolescent students in Harari people's regional state.

Accordingly, adolescents' students were participated in the present study result was indicated that they were low in assertiveness. Male adolescents were found to be better in their levels of assertiveness than their female students' counterparts. On the other hand, the relationship between assertiveness and academic achievement motivation were found positive and significant. This implied that as adolescents' level of assertiveness increases, their academic achievement motivation increases too

Moreover, it was concluded that there was positive significant relationship between parental educational status and assertiveness. This perhaps because educated parents more likely to allow their children to discuss their concerns openly and encouraged to say no on matters they must say no and yes on matters they supposed to say yes which in turn cultivates a habit of assertiveness in their children. Unlike assertiveness and parental educational status, sex appeared to be less important factors in explaining adolescents' academic achievement motivation.

The following suggestions would help address the gaps noted. Because to be successful in all aspects of life especially in academic endeavor, adolescents need to be assertive enough. Therefore, psychologists, school counselors, teachers, and school directors need to provide assertiveness training to build acceptable assertive behavior among adolescent students. Besides, orientation on the importance of being assertive should be given to parents so that they can help their children develop the assertive behavior. Special attention by psychologist, parents, teachers, and counselors should be given to female adolescents in instilling assertive behavior in them as of in Ethiopian culture females are detected to be submissive which finally leave them to the low level of assertiveness. Government should plan strategies on assertiveness training skill for high school students in such away we would have assertive enough youngsters. Further research be conducted on the role of gender in assertiveness to clear possible inconsistencies noted in this and many other research. 


\section{REFERENCES}

Belay, T. \& Galata, S. (2016). Family structure and academic achievement motivation of adolescent students in Haramaya secondary and preparatory school students, east Hararghe Ethiopia. East African journal of social science and humanities, 5(1), 201-220.

Elma, S. (2017). Assertiveness, self-esteem and academic performance in speech and oral communication of Filipino junior secondary teacher education students. Asia Pacific Journal of Multidisciplinary Research,5(3), 36-42.

Eskin, M. (2003). Self-reported assertiveness in Swedish and Turkish adolescents: A cross- cultural comparison. Second Journal of Psychology, 44(1), 7-12.

Galassi, J. P., Delo, J. S., Galassi, M. D., \& Bastien, S. (1994). The College of self-expression scale: A measure of assertiveness. Behavior Therapy, 5(2), 165-171. doi:10.1016/S0005-7894(74)80131-0

Ghodrati, F., Tavakoli, P., Heydari, M., Akbarzadeh, N. (2016). Investigating the relationship between self-esteem, assertiveness and academic achievement in female high school students. Health Science Journal,10(4), 1-5.

Huurre, T., Aro, H., Rahkonen, O., \& Komulainen, E. (2006). Health, lifestyle, family and school factors in adolescence: Predicting adult educational level. Educational Research,48(1), 41-53.
Kifle, G. K. (2004). Self-efficacy, academic achievement motivation and study habits as related to general secondary school students' academic performance: The case of general secondary school students in Tigray (Unpublished MA Thesis), AAU, Addis Ababa.

McClelland, D. (1985). Human motivation. Glenview: Scott, Forseman and Company.

Moon, J. (2009). Academic assertiveness real life strategies for today's higher education students. New York: Routledge Taylor \& Francis group.

Mulugeta, T. (1998). Locus of control, self-efficacy \& academic achievement motivation a predictors of academic performance of college freshman: The case of AAU (Unpublished MA Thesis). AAU. Addis Ababa.

Oladipo, A., Arigbabu, A., \& Rufai K. (2012). Gender, need-achievement and assertiveness as factors of conceptions about math among secondary school students in Ogun state, Nigeria. Review of European Studies, 4(4), 141-147.

Rathus, S. A. (1998). An experimental investigation of assertive training in a group setting. Journal of Behavior Therapy and Experimental Psychiatry, 3(2), 81-86.

Turner, B. (1992). Gender difference in old age in rating of aggression/assertiveness. Current Psychology, 11(2), $122-127$. 